Neues Verfahren zur Reinigung der Benzoesäure;

von

Giovanni Righini.

Die zu reinigende Benzuesäure löst man in 4 bis 5 Theilen Schwefelsäure auf, die mit 6 Theilen Wasser verdünnt worden ist, setzt während dem Kochen eine kleine Quantität reinster Thierkohle hinzu und filtrirt; nach dem Erkalten scheidet sich die Säure in schönen Krystallen aus. Wenn die Krystalle keine schöne und lange Nadeln bilden, oder noch etwas Geruch haben, so wiederholt man das vorstehende Verfahren nochmals. Man sammelt die Krystalle auf einem Filter, wäscht sie aus, um die anhängende Schwefelsäure zu entfernen, und trocknet sie im Schatten. Die Schwefelsäure hat alles Harz und Oel, welches die Benzoesäure verunreinigte, aufgelöst, so dass diese ganz frei davon ist.

Um die Säure in schönen Krystallen zu erhalten, löst man sie nach der Sältigung mit Alkohol auf und stellt die Auflösung in einen Sublimationsapparat auf ein Sandbad und leitet das Feuer der Art, dass der Alkohol sich allein verflüchtigt, worauf die Benzoesäure in langen völlig weissen und geruchlosen Nadeln zurückbleibt.

Eine vortheilhafte Art, das Eieröl (Oleum ovorum) zu bereiten;

rom

Apotheker Röttscher

in Wiedenbrück.

Eigentlich habe ich schon einen Vorgänger, der das 
Eieröl mit Aether (ohne Pressen) darzustellen suchte *), allein da mein Verfahren von einem früher angegebenen abweicht, so glaube ich es meinen Collegen mittheilen zu müssen. Man nimmt sechszig Hühnereier, kocht sie hart, macht das Gelbe heraus, und erhitzt es so lange unter stetem Umrühren, bis es ein bräunliches Ansehen erhalten hat und zum Pressen tauglich geworden ist. Man lässt es hierauf erkalten, überschültet es mit 16 Unzen Aether, lässt 24 Stunden kalt digeriren, giesst das Flüssige durch ein Wolltuch und presst aus. Die erhaltene Flüssigkeit wird hierauf klar abgegossen, und der Aether bei gelinder Wärme verdunstet. Die ätherische Lösung pflegt während dem Verdunsten sehr zu steigen, welches wahrscheinlich vom Stearin des Oels herrührt, weshalb es besser ist, den Aether verdampfen zu lassen, und nicht abzudestilliren. Ich erhielt von 6o Eiern sieben Unzen zwei Drachmen eines sehr schönen Oels.

\section{Ueber Silberoxydborat;}

$$
\text { Dr. du Mênil. }
$$

Bei Untersuchung des Datoliths vom Harz * fand ich, dass sich die Boronsäure eines Salzes derselben, mittelst Silberoxydnitrat bis auf einen geringen, fast zu übersehenden Rückhalt abtrennen lasse, und neuerdings belehrte ich mich, dass ein Theil Silberoxydborat, wie es aus der Solution eines

*) Vergl. auch die Bd. II. der zweiten Reihe dieser Zeitschrift S. 157 mitgetheilten Bemerkungen von Geiseler.

Die Red.

**) Schweigger's Jahrbuch der Chemie und Physik 1828. 364. 